\title{
Demoulding Force Prediction for Micro Polymer Replication: A Review of Relevant Literature
}

\author{
Kevin Delaney \\ Technological University Dublin, kevin.delaney@tudublin.ie \\ G. Bissacco . \\ Technical University of Denmark \\ David Kennedy \\ Technological University Dublin, david.kennedy@tudublin.ie
}

Follow this and additional works at: https://arrow.tudublin.ie/engschmeccon

Part of the Engineering Commons

\section{Recommended Citation 978-981-08-6555-9_149 \\ This Conference Paper is brought to you for free and open access by the School of Mechanical and Design Engineering at ARROW@TU Dublin. It has been accepted for inclusion in Conference Papers by an authorized administrator of ARROW@TU Dublin. For more information, please contact arrow.admin@tudublin.ie, aisling.coyne@tudublin.ie, gerard.connolly@tudublin.ie.}

Delaney, K., Bissacco, G., Kennedy, D.:Demoulding Force Prediction for Micro Polymer Replication: A Review of Relevant Literature. Proceedings of the 7th. International Conference on Multi-Material Micro Manufacture (Fillon, B., Khan-Malek, Dimov, S. eds). Research Publishing, 2011. doi:10.3850/

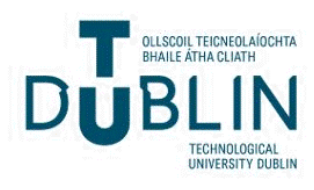




\title{
Demoulding force prediction for micro polymer replication: a review of relevant literature
}

\author{
K.D. Delaney ${ }^{a}$, G. Bissacco ${ }^{b}$, D. Kennedy \\ ${ }^{a}$ Dublin Institute of Technology, Dublin, Ireland \\ ${ }^{\mathrm{b}}$ Department of Innovation in Mechanics and Management, University of Padova, Italy
}

\begin{abstract}
Demoulding components without damage to either the components or tool is critical to successful replication processes. During tooling development designers strive to optimize replication tools to minimize demoulding force and resultant stress on replicated parts. A critical element of this process is an accurate demoulding force prediction model. Various models have been proposed to predict demoulding forces, each showing limitations in its applicability. This paper reviews existing demoulding force models and parameters affecting demoulding force for micro polymer replication.
\end{abstract}

Keywords: demoulding force, ejection, micro replication

\section{Introduction}

When a replicated part reaches a condition that it will remain stable outside of the tool it is forcibly demoulded or ejected from the replication tool typically using a series of ejector pins. An applied force is needed to overcome retarding forces which develop at the component and tool interface due to friction and adhesion.

As part size reduces, the potential sites where ejection pins can act are reduced and parts become weaker and more prone to damage when mechanically stripped from tool cores. To prevent failure the component and tool must not be overly stressed or damaged during the application of this ejection force. Theoretical models relating to the ejection of parts from replication tools should predict one or more of the following:

- Actual demoulding force

- Stress levels within the component

- Stress levels within the replication tooling This enables designers to optimize replication tools to minimize the demoulding force and resultant stress on replicated parts.

Demoulding failure results from shear stress due to friction and thermally-induced stress due to cooling. This paper defines "demoulding force" as that necessary to initiate the ejection movement of the part only, thereby not including frictional effects from the ejection mechanism. This paper presents a condensed critical review of existing demoulding force models for micro polymer replication. The primary focus is on models which can be used to predict the actual demoulding force.

\section{Demoulding stresses}

During the cooling phase of a replication process, parts shrink onto and are constrained by the replication tool. This shrinkage causes stress to build up in the cross section of the part [1] and results in the generation of forces normal to the surfaces restrained from shrinking. The stresses which develop are strongly related to normal pressure and therefore to shrinkage, part stiffness and mould packing. A tangential force is required to overcome the effect of such normal forces and generate relative motion between the part and tool during part demoulding.

Micro replicated parts are delicate and prone to damage by such applied forces. Micro replication also introduces challenges for the structural strength of replication tools, specifically the micro cores needed for high aspect ratio parts. When an ejection force is applied after replicated parts have shrunk onto the core there is a risk that the core may break. This will occur if the force applied by the ejector pins develops a tensile stress greater than the core tensile strength as shown in [2]. Additional problems may arise if there is no draft angle.

While the situation described refers to replicated parts shrinking onto cores, the demoulding of pillartype structures is also complex since such parts have a reduced structural strength. High normal stresses can develop at the base of such pillars while tangential stresses can develop across the face of the pillar due to shrinkage of the supporting substrate.

\section{Factors affecting demoulding force}

The forces described in the previous section refer to those resulting from contact pressure between the tool and replicated part. If atmospheric pressure does not exist between the part and core during demoulding a suction force may be generated. 
This is the product of atmospheric pressure and surface area on the top of the core. Fig. 1 illustrates these primary demoulding force components.

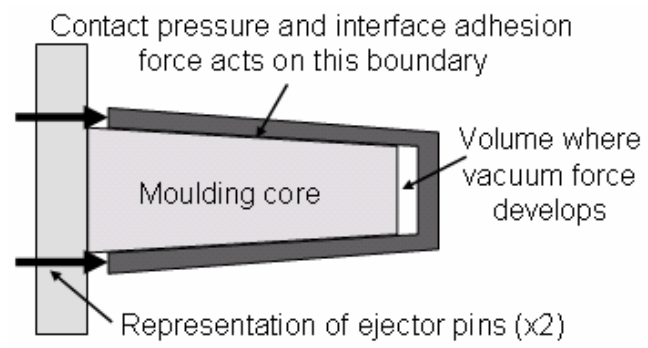

Fig. 1: Primary contributors to demoulding force.

The demoulding of parts is complex with many influencing factors. Burke and Malloy [3] highlighted the difficulties in defining the coefficient of friction and contact pressure since both depend on processing, material, product and mould design variables. Attempts to identify the most significant parameters have involved both experimental and simulated replication trials.

Differential shrinkage coefficients between the replication tool and the material give rise to contact pressure. The tool and replicating material will also affect the amount of wetting between the tool and part.

Sasaki et al [4] confirmed an optimum roughness for the core which minimizes the ejection force exists. This is consistent with experimental results by Grosch [5] who concluded that friction on smooth and rough surfaces is from different mechanisms. That on smooth surfaces is attributed to "adhesion" and that on rough surfaces to "deformation".

The importance of the surface finishing direction was highlighted by several including Burke and Malloy and Worgull et al $(2006)[3,6]$. Intermittent tool smearing which may result from tool fabrication, such as with micro milling, increases the degree of mechanical interlocking.

It is noted that the tool surface condition may change during processing. Packham highlighted a number of the problems associated with mould sticking and fouling [7]. Mould fouling relates to the build-up of deposits on the mould surface after a number of moulding cycles. The use of release agents can be suitable for larger components but may not be suitable for micro replication processes since replication dimensions may be affected.

\section{Theoretical studies on demoulding force}

This section summarizes mathematical models for the demoulding of parts from replication tools developed by several researchers. Most derive from the empirical law of Coulomb friction [1]. For parts which shrink onto cores, such as sleeves or boxshaped parts, the release force $F_{R}$ is given by the Menges and Mohren model [1] as:

$$
F_{R}=\mu \times P_{A} \times A_{C}
$$

Where $\mu$ is the coefficient of friction $P_{A}$ is the contact pressure and $A_{C}$ the area of contact. The magnitude of $\mu$ depends upon several factors and is discussed further in section 6 . An outline of demoulding force models based on Coulomb's law is shown in Fig. 2. While the nominal contact area can be measured relatively easily the friction coefficient and contact pressure can have various interpretations.

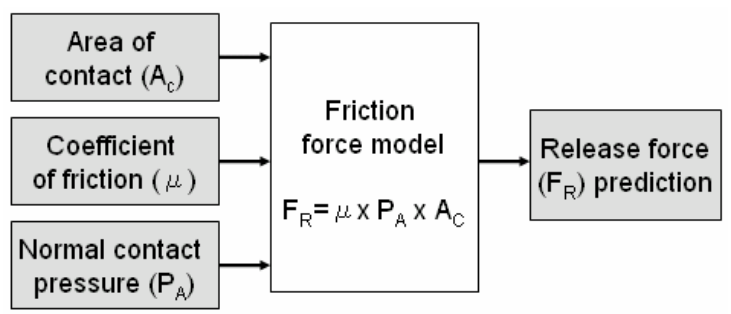

Fig. 2: Coulombic friction force model.

After demoulding a cylindrical part the relative change in circumference can be used as a measure of tensile strain in the part cross section when still on the core. This strain, multiplied by the elastic modulus, the surface in contact and a friction coefficient gives an estimate of the force required to demould the part resulting in the equation:

$$
F_{R}=\mu \times E(T) \times \Delta d_{r} \times t \times 2 \pi L
$$

Where $E(T)$ is the elastic modulus of the thermoplastic material at ejection temperature, $L$ the length of part in contact with the mould core, $\Delta \mathrm{d}_{\mathrm{r}}$ the relative decrease in part diameter and the thickness.

Using a similar equation Glanvill and Denton [8] described how to calculate the demoulding force for rectangular moldings. The shrinkage coefficient and temperature difference between the part's melt and ejection temperature were explicitly included.

The layered structure of stereolithographic tools may be compared to the periodic profile of mould surfaces produced by, for example, micro milling. A layered fabrication process means that stereolithographic tools have a large inherent surface roughness. During part demoulding the deformation mechanism dominates due to the level of interlocking of the replicant and replicating tool. In 2001 Colton et al presented a model [9], later implemented by Pham and Colton (2002) [10], to quantify the ejection force for parts replicated with stereolithographic tools. Thermal shrinkage and the inherent stair-step profile which creates an undercut or overlap between the part and mould were included. The friction coefficient is increased to account for the deformation needed for the mould and polymer parts to elastically deform sufficiently to slide over each other and overcome this overlap. This model was recently applied to nonstereolithographic tools with a periodic mould surface profile by the authors [11].

Pontes et al (2005) [12] presented a thermomechanical model to predict ejection force. This model assumed the existence of a friction coefficient and that polymers change from purely viscous to 
purely elastic below a transition point.

\section{Experimental studies on demoulding force}

This section summarizes experimental studies of demoulding force according to replication process.

\subsection{Injection moulding}

Wang et al [13] studied the ejection process to optimize ejector pin layouts. The overall ejection force was distributed among the ejector pins.

Pontes et al [14] developed an instrumented research mould for tubular mouldings $(60 \mathrm{~mm}$ in diameter, $146 \mathrm{~mm}$ long and $2 \mathrm{~mm}$ thick). Results presented show that ejection force changes inversely with holding pressure due to decreasing diametrical shrinkage. Holding time did not affect ejection force. For the same tubular geometry Pontes and Pouzada [12] presented results on how the ejection force varies with processing conditions for amorphous (PC and PS) and semi-crystalline (PP) polymer. Core surface temperature substantially influences the ejection force. As the surface temperature increases the force was found to decrease at a rate of approximately $40 \mathrm{~N} /{ }^{\circ} \mathrm{C}$ for $\mathrm{PP}$ and $60 \mathrm{~N} /{ }^{\circ} \mathrm{C}$ for $\mathrm{PS}$. This is caused by reduced modulus and shrinkage, and thus less contact pressure at ejection due to an increased material temperature. Higher mould temperatures increase the mechanical interlocking increasing $\mu$. There is an injection temperature that minimizes the ejection force.

Bhagavatula et al [15] compared results from the Menges and Mohren model [1], an ANSYS simulation and experimental results. A cylindrical canister with a height of 49.5, thickness of 0.5 and inner-radius of $15 \mathrm{~mm}$ was moulded. Non-isothermal conditions were assumed for simulation. Ejection force was measured as melt temperature, packing pressure and packing time were modified. Packing pressure had greatest effect on ejection force.

In 2005 Bataineh and Klamecki [16] proposed a system to predict local mould-part forces and the resulting local and total ejection forces needed for part ejection.

Griffiths et al [17] used design of experiments to study the demoulding of a micro fluidics part as a function of tool surface treatment and process parameters. Process parameters studied were the barrel and mould temperature, the cooling time after part filling and the use of a delay to control the ejection time. Surface treatments, particularly DLC, were found to significantly reduce the demoulding force and improve part quality. The absence of a unique selection of parameter levels to optimize demoulding behavior for the surface treatment and polymers investigated was highlighted.

Michaeli and Gärtner proposed alternative nondestructive methods to demould microstructures without ejector pins [18]. Alternative methods trialled were demoulding with ultrasonics, demoulding with vacuum and accurate retreat of a cavity. Only accurate retreat of the cavity was deemed to be a successful method for demoulding. It is noted that a commercial micro injection moulding machine supplier now offers machines with an option to demould micro components using ultrasonics [19].

\subsection{Embossing}

As part of a larger project to improve the micro embossing process Worgull et al [20] proposed reducing warpage and shrinkage of the moulded part using a frame to stop the flow front during moulding. Sacrificial features outside the functional area were proposed to protect the remaining features. Worgull et al [21] presented a contact and friction model to simulate friction during the demoulding phase. The existence of a static friction coefficient is assumed. Worgull et al [22] presented results regarding the modelling and simulation of large area replication based on an eight inch microstructured mould.

Guo et al [23] studied the demoulding process and highlighted the implications for thermal stress, adhesion and friction control. An auxiliary thermal stress barrier, similar to that proposed by Worgull et al [20], was proposed to protect the microstructures. In addition the use of Ni-PTFE as a mould material was recommended to achieve lower surface energy and friction force. Simulated results were presented by Guo et al [24].

\section{Determining a suitable coefficient of friction}

Experimental work to determine a suitable coefficient of friction has been performed by several authors using simulated replication trials. The effect of varying the mould temperature, surface roughness, replicating pressure and ejection velocity on the coefficient of friction has been studied.

Ferreira et al [25] developed an apparatus to study the effect of different parameters on the coefficient of friction relevant for the ejection of plastic parts from moulds. In related work Ferreira at al [26], studied the effect of polish direction, surface roughness and test temperature on the coefficient of friction. Results showed that testing temperature and surface roughness had a significant effect on the coefficient of friction for PC. No parameters studied had a significant effect on the coefficient of friction for $\mathrm{PP}$, except possibly the interaction of polish direction and roughness. In general the coefficients of static friction observed for PC and PP are larger than previously published data.

Pouzada et al [27] studied the static coefficient of friction under moulding conditions. The equipment developed enabled the determination of an optimal surface roughness that corresponds to the minimum coefficient of static friction. The test data obtained was sensitive to temperature, the surface roughness and the pressure between the contacting surfaces.

Worgull et al $[6,28]$ observed that demoulding forces may vary by several factors depending on the process parameters selected and the quality of the tool. A test apparatus which can be used in a tensile testing machine was described and results presented 
based on varying parameters. Friction test results by Worgull et al show the static coefficient of friction increases as the velocity decreases.

Taking a different approach Bataineh and Klamecki performed demoulding experiments of ring shaped geometries to obtain friction coefficients [16].

Berger et al [29] described an injection mould with integrated friction test device to compare how parameters such as mould material and surface, the polymer and actual processing conditions used influence the static coefficient of friction. Decreasing roughness of non-coated mould inserts increased the $\mu_{0}$ while increasing the cooling temperature decreased $\mu_{0}$. As the vertical force increased $\mu_{0}$ first increased then stay constant or slightly decreased.

\section{Conclusions}

This paper presents a condensed critical review of existing demoulding force models for micro polymer replication. Modeling of demoulding forces still depends on the determination of a coefficient of friction. This approach is not suitable to explain the complex phenomena occurring at the interface between the replication tool and part.

There is therefore a need for a more fundamental approach in order to enable the development of a robust model applicable to different processes and processing conditions. An effort towards the development of such a model is ongoing at the authors' institutions.

\section{Acknowledgements}

Financial support from DIT's Directorate of Research and Enterprise is acknowledged.

\section{References}

[1] Menges G. and Mohren P., How to Make Injection Moulds, Hanser, New York, 1993, 388.

[2] Hopkinson N. and Dickens P.M., Proceedings of the IMechE, Part B, (2000) 891-899.

[3] Burke C. and Malloy R., ANTEC'91, (1991) 17817.

[4] Sasaki T., Koga N., Shirai K., Kobayashi Y. and Toyoshima A., Precision Eng., 24,(2000) 270-273.

[5] Grosch KA., Proc. Roy. Soc. Lond. A 274 (1963) 21-39.

[6] Worgull M., Hétu J.F., Kabanemi K.K., and Heckele M., DTIP of MEMS and MOEMS, Stresa, Italy, (2006)

[7] Packham D., "Mould Sticking, Fouling and Cleaning", Smithers Rapra Technology, (2002).

[8] Glanvill A.B. and Denton E.N., Injection-mould Design Fundamentals, London, Machinery Publishing Co. 1963.

[9] Colton J.S., Crawford J., Pham G., Rodet V., Annals of CIRP, 50, (2001) 129-132.

[10] Pham G.T. and Colton J.S., Polymer Engineering and Science, 42, (2002) 681-93.
[11] Delaney K., Bissacco G. and Kennedy D., ANTEC 2010, (2010) 2149 - 2154.

[12] Pontes A.J., Pouzada A.S., Pantani R. and Titomanlio G., Polymer Engineering and Science (2005) 325-332

[13] Wang H., Kabanemi K., and Salloum G., Journal of Polymer Engineering Science, 40, (2000) 826840

[14] Pontes A.J., Brito A.M., Pouzada A.S., Journal of Injection Molding Technology, vol, 6: n6 (2002), 343-352.

[15] Bhagavatula N., Michalski D., Lilly B. and Glozer G., Modelling Simul. Mater. Sci. Eng. 12 (2004) S239-S254

[16] Bataineh O.M. and Klamecki B.E., ASME journal of Manufacturing Science and Engineering, 127, (2005) 598-604

[17] Griffiths C.A., Dimov S.S., Brousseau E.B., Chouquet C., Gavillet J. and Bigot S. Investigation of surface treatment effects in micro-injectionmoulding. International Journal of Advanced Manufacturing Technology, Vol. 47 (1-4), 2010, pp. $99-110$

[18] W. Michaeli, R. Gärtner, New demolding concepts or the injection molding of microstructures, Journal of Polymer Engineering, vol. 26, Nos 2-4, 2006, pp. 161-177

[19]http://www.europeanplasticsnews.com/subscriber/ newscat 2 . html ?cat $=1$ \&channel $=200 \&$ id $=1265881$ 624

[20] Worgull M, Heckele M and Schomburg WK, Microsystem Technologies, 12, 1-2, (2005) pp110-115

[21] Worgull M, Heckele M, Hétu JF and Kabanemi KK, , J. Microlith., Microfab., Microsyst., 5, (2006), 011005.

[22] Worgull M, Kabanemi KK, Marcotte JP, Hétu JF and Heckele M, Microsystem Technology, 14, (2008) 1061-1066.

[23] Guo $Y$, Liu G, Xiong $Y$ and Tian $Y$, Journal of Micromechanics and Microengineering, 17, (2007) 9-19.

[24] Guo Y, Liu G, Zhu X and Tian Y, Microsystem Technology, 13,(2007) 411-415

[25] Ferreira EC, Neves NM, Muschalle R and Pouzada AS, ANTEC (2001), 1546-1549

[26] Ferreira EC, Muschalle R, Neves NM and Pouzada AS, ANTEC 2002.

[27] Pouzada AS, Ferreira EC and Pontes AJ, Polymer Testing 25, (2006) 1017-1023.

[28] Worgull M., Hétu J.F., Kabanemi K.K. and Heckele M., 14, (2008) 767-773.

[29] Berger G.R., Friesenbichler, W., Schöfer, G. and FreudenschuB, G. ANTEC 2009, (2009) 16991703. 